Research Article

\title{
A Simplified Approach to Estimating the Collapsible Behavior of Loess
}

\author{
Hua Wen $\mathbb{D}^{1},{ }^{1}$ Songyin Deng $\mathbb{D}^{1},{ }^{1}$ Wei Zhang $\mathbb{D}^{2},{ }^{2}$ Qiangong Cheng $\mathbb{D}^{3},{ }^{3}$ Jiujiang Wu $\mathbb{D}^{1,4}$ \\ and Dailin $\mathrm{Hu}$ (D) \\ ${ }^{1}$ Shock and Vibration of Engineering Material and Structure Key Laboratory of Sichuan Province, \\ Southwest University of Science and Technology, 59 Qinglong Ave Middle Section, Fucheng Qu, Mianyang, \\ Sichuan 621010, China \\ ${ }^{2}$ Kunming Metallurgy College, W 3rd Ring Road, Wuhua Qu, Kunming, Yunnan 650033, China \\ ${ }^{3}$ Faculty of Geosciences and Environmental Engineering, Southwest Jiaotong University, No. 111, North 1st Section, \\ 2nd Ring Road, Chengdu, Sichuan 611756, China \\ ${ }^{4}$ Department of Civil and Environmental Engineering, Western University, 1151 Richmond Street, London, ON, Canada
}

Correspondence should be addressed to Jiujiang Wu; wujiujiang1988@126.com

Received 6 September 2019; Revised 11 November 2020; Accepted 26 November 2020; Published 10 December 2020

Academic Editor: Guang-Liang Feng

Copyright $\odot 2020$ Hua Wen et al. This is an open access article distributed under the Creative Commons Attribution License, which permits unrestricted use, distribution, and reproduction in any medium, provided the original work is properly cited.

Due to the particularity and complexity of loess, it is challenging to estimate its collapsible behavior numerically at present. This paper aims to propose a simplified approach, which is named as the modulus reduction method, to estimate the collapsible behavior of loess. For loess upon wetting, the modulus reduction method assumes that loess collapses as a result of strength reduction due to the additional stress induced by increasing bulk density. Thus, special attention is given to the confirmation and determination approaches of bulk density and deformation modulus of loess upon wetting. Subsequently, a comparative numerical analysis based on the modulus reduction method and the force-water equivalent method, which is commonly used for the analysis of negative skin friction on piles in collapsible soil, is investigated. It turns out that the result obtained by the modulus reduction method is more consistent with the collapse mechanism of loess compared with that derived by the force-water equivalent method. Finally, a case history concerning a published field test of loess upon wetting is studied, and the result shows that the simulated deformation characteristics by adopting the modulus reduction method agree excellently well with the measured data. The case study validates that the modulus reduction method is feasible to analyze the collapse of loess and suitable for the numerical simulation involving collapsible loess.

\section{Introduction}

As the essential collapsible soil, loess and its collapsibility are constantly concerned by engineers and researchers. There are many methods that can be used to investigate the collapsibility of loess. For instance, the in situ test and field wetting test can directly measure the deformation amount and estimate the deformation characteristics of collapsible loess, and the obtained test data are accurate and reliable. Scholars [1-5] have implemented a significant number of field wetting tests in different areas to collect valuable measured data. The field wetting test conducted in Pucheng
Power Plant in Shaanxi Province, China, is one of the representatives [2]. Nevertheless, field test requires high expense, considerable manpower, and long duration.

Numerical simulation is widely used to study the negative skin friction (NSF) of pile foundations, and a significant number of these numerical simulations are focused on soft soil foundation [6-10]. In order to realize the occurrence of negative skin friction, the uniform load is applied on the surface of the soil to ensure that the vertical displacement of soil is more significant than that of the pile in these simulations. With respect to pile foundations in collapsible loess, it is unreasonable to apply the commonly used 
methods for piles in the softs soil to simulate the NSF induced by the collapse of loess under overburden pressure. Due to the particularity and complexity of the collapse mechanism of loess, it is challenging to simulate its collapsible behavior, and relevant numerical analysis concerning NSF of pile foundation induced by collapsible loess under overburden pressure is rarely reported [11]. The behavior estimation of collapsible loess under overburden pressure is critical to facilitate the numerical analysis of NSF on piles in collapsible loess.

At present, numerous efforts have been made to estimate the collapsible behavior of loess under overburden pressure. Many constitutive models of collapsible loess have been developed accordingly. Zhou et al. [12] established an incremental constitutive relation based on the generalized plasticity through analyzing the plastic properties of collapsible deformation of loess. Garakani et al. [13] presented an empirical model for explaining the load-collapse behavior of lime-stabilized tested soil, and the results show excellent conformance between the laboratory test results and model prediction. Hu et al. [14] proposed a constitutive mathematical model of unsaturated natural loess in which the loading process and other properties can be simulated. $\mathrm{Xu}$ et al. [15] proposed an elastoplastic constitutive model considering the effects of temperature and strain rate to describe the strength and deformation behavior of frozen Helin loess. It should be noted that most of the constitutive models are developed based on the results from conventional tests and consists of complex forms/matrix and numerous parameters which hinder their application. Considering these, some simplified methods, which can be conveniently used in the numerical analysis software, are generated. Li [16] attempted to simulate the loess collapse by applying additional gravity on the collapsible soil layers, which did not conform to the actual condition. For collapsible loess with stable deformation (compressive deformation and shear deformation), the deformation of loess is strengthened or the strength of loess is reduced only by increasing the stress level or the water content of the loess at a specific stress level (normal stress and shear stress). Mustayev [17] suggested that the collapse of loess can be transformed into the deformation induced by the uniform load applied on the surface of loess. This perspective, whose principle conforms to the NSF analysis of piles in soft soil, was then developed into a simplified approach to estimating the collapsible deformation of loess and can be named as the force-water equivalent method. However, the collapse of loess under overburden pressure belongs to plastic deformation induced by wetting instead of external loading on the surface.

In this paper, the physical and mechanical properties of loess, as well as its collapsible mechanism and deformation characteristics, are investigated and discussed initially. Subsequently, a simplified method named as the modulus reduction method based on the principle of strength reduction is proposed to simulate the collapsible behavior of loess. Concerning loess upon wetting, the proposed approach assumes that loess collapses as a result of strength reduction due to the additional stress induced by increasing bulk density. Thus, special attention is given to the discussion on the bulk density and deformation modulus of loess upon wetting. By utilizing the finite-differential-element code of FLAC3D, comparative numerical analyses that adopt the modulus reduction method as well as a commonly used method are carried out based on the same numerical model. Finally, a case history concerning the field test of loess upon wetting in Pucheng Power Plant is studied, and the calculated results derived by the modules reduction method are compared with the measured data accordingly.

\section{The Proposal of the Modulus Reduction Method}

2.1. Outline of the Modulus Reduction Method. During the collapse process of loess upon wetting, that is, loess from partly saturated to fully saturated, the void ratio of loess reduces while the bulk density increases. Moreover, the compressive strength (deformation modulus) and shear strength of loess continually decrease as the water content increases. In other words, all the strength parameters (including deformation modulus $E_{0}$, cohesion $c$, and internal friction angle $\varphi$ ) decrease with the increment of water content while the bulk density ascends as water content increases $[18,19]$. At this point, a new simplified method based on the principle of strength reduction to simulate the collapse of loess under overburden pressure can be proposed by assuming that the bulk density of loess increases while the strength parameters reduce due to wetting. Under this circumstance, the deformation of loess with reduced strength parameters under the additional stress induced by increasing bulk density can be treated as the collapsible deformation.

Typically, the reduction of strength parameters can be divided into three conditions:

(1) Reduction of shear strengths for $c$ and $\varphi$.

(2) The reduction of compressive strength $E_{0}$.

(3) The reduction of $E_{0}, c$, and $\varphi$.

The first condition involves the well-known strength reduction method, which is frequently applied in the stability analysis of slope engineering. The shear strength parameters $c$ and $\varphi$ are mainly used to analyze the stability of soil and foundation while the compressive strength (deformation modulus) $E_{0}$ is intensively applied to calculate the deformation of foundation [19]. In this paper, the reduction of strength parameter on loess is conducted on the second condition, that is, only reducing the deformation modulus $E_{0}$. Therefore, the simplified approach proposed in this paper can be named as the modulus reduction method.

Through the above analysis, it can be seen that the bulk density and deformation modulus of loess are the most crucial parameters of the modulus reduction method to simulate the collapsible loess under overburden pressure. Therefore, the modulus reduction method can be simply expressed by the following two formulae: 


$$
\begin{aligned}
\gamma_{s} & =\gamma_{0}+\Delta \gamma, \\
E_{0 s} & =\zeta \cdot E_{0},
\end{aligned}
$$

where $\gamma_{s}$ and $E_{0 s}$ represent the bulk density of loess and the deformation modulus of loess upon wetting, respectively. $\gamma_{0}$, $\Delta \gamma, \zeta$, and $E_{0}$ refer to the initial bulk density, increased bulk density induced by wetting, reduction factor (generally less than 1), and the initial deformation modulus, respectively.

Concerning the modulus reduction method, the changes of shear strengths $(c$ and $\varphi$ ), Poisson's ratio $v$, and void ratio $e$ are not taken into account. In other words, when conducting model calculation by using numerical simulation software (such as FLAC3D), the collapse of loess under overburden pressure is simulated only by adjusting the bulk density and deformation modulus of soil in a specific area, and the values of $c$ and $\varphi$ as well as $v$ and $e$ will remain unchanged.

2.2. Determination of Bulk Density. According to equations (1) and (2), the key to the modulus reduction method is to determine the two parameters, that is, $\gamma_{s}$ and $E_{0 s}$. To obtain the bulk density $\gamma_{s}$, the increased bulk density $\Delta \gamma$ should be calculated in advance as

$$
\Delta \gamma=\gamma_{s}-\gamma_{0}
$$

It is assumed that the void ratio $e$ remains unchanged during the collapse process of loess. When the water content of loess increases from $\omega_{0}$ to $\omega_{s}$ during the collapse process, the saturability of loess increases from $S_{r 0}$ to $S_{r s}$ accordingly. Based on the conversion relation between the bulk density and saturability [20], the following formulae can be acquired:

$$
\begin{aligned}
& \gamma_{0}=\frac{d_{s}+S_{\gamma 0} \cdot e}{1+e} \gamma_{w}, \\
& \gamma_{s}=\frac{d_{s}+S_{\gamma s} \cdot e}{1+e} \gamma_{w},
\end{aligned}
$$

where $d_{s}$ and $\gamma_{w}$ refer to the specific gravity of soil particles and natural gravity of water, respectively.

By substituting equations (4) and (5) into equation (3), equation (6) can be attained.

$$
\Delta \gamma=\frac{e \cdot\left(S_{\gamma s}-S_{\gamma 0}\right)}{1+e} \gamma_{w}
$$

According to the relationship between the saturation and the water content, equation (7) can be acquired.

$$
S_{\gamma}=\frac{\omega \cdot d_{s}}{e}
$$

Substitute equation (7) into equation (6), then

$$
\Delta \gamma=\frac{e \cdot S_{\gamma s}-\omega \cdot d_{s}}{1+e} \gamma_{\omega} .
$$

Based on equation (8), the increased bulk density $\Delta \gamma$ can be calculated. If the initial water content and void ratio of loess and the saturability of loess after the collapse are known, the increased bulk density $\Delta \gamma$ can be attained through equation (8), and then the bulk density $\gamma_{s}$ of collapsible loess can be obtained at last.

\subsection{Determination of Deformation Modulus $E_{0}$}

2.3.1. Confirmation of Deformation Modulus. For FLAC3D, all material models are supposed to have isotropic material behavior in the elastic stage except for the transversely isotropic elastic model and orthogonal anisotropic elastic model. Moreover, the elastic behavior is characterized by bulk modulus $K$ and shear modulus $G$, which can be obtained through conversion based on Young's modulus $E$ and Poisson's ratio $v[21]$ :

$$
\begin{aligned}
& K=\frac{E}{3(1-2 v)}, \\
& G=\frac{E}{2(1+\nu)} .
\end{aligned}
$$

For soil, the deformation modulus $E_{0}$ of soil shows the same definition as the elastic modulus (Young's modulus) $E$ in general elastic theory [20]. However, the soil is not always subjected to elastic deformation and likely undergoes plastic deformation. Therefore, the elastic modulus of soil is generally called the deformation modulus.

\subsubsection{Relationship between Compressive and Deformation} Modulus for Loess. The compressive modulus $E_{s}$ denotes the ratio of stress $\sigma_{z}$ on soil under lateral confinement to the unit strain $\varepsilon_{z}$, which is expressed as follows:

$$
E_{S}=\frac{\sigma_{Z}}{\varepsilon_{Z}} .
$$

In a triaxial compression test, $\sigma_{z}=\Delta p=p_{2}-p_{1}$ and $\varepsilon_{z}=\Delta H / H_{0}=\Delta e /\left(1+e_{0}\right)$. Based on the compression law, the compressibility $a=\Delta e / \Delta p$. Then, equation (10) can be transformed into

$$
E_{S}=\frac{\Delta p}{\Delta e /\left(1+e_{0}\right)}=\frac{1+e_{0}}{a} .
$$

The deformation modulus $E_{0}$ of soil represents the ratio of the stress acting on homogeneous isotropic linear-elastic soil in half-space without lateral confinement to the unit strain. $E_{0}$ can be derived from $E_{s}[19]$ by

$$
\left.E_{0}=E_{S}\left(1-\frac{2 v^{2}}{1-v}\right)\right)=E_{S}\left(1-2 v k_{0}\right),
$$

where $k_{0}$ is the intermediate variable, which equals $v /(1-v)$.

Set $\beta=\left(1-\left(2 v^{2} / 1-v\right)\right)=\left(1-2 v k_{0}\right)$, and then

$$
E_{0}=\beta E_{S} \text {. }
$$

Theoretically, the value of $\beta$ should always be lower than 1. Nevertheless, the measured $E_{0}$ of soil is practically more substantial than $E_{s}$, which indicates that $\beta$ is generally larger than 1. Guan [22] has investigated the values of $E_{0}$ and $E_{\mathrm{s}}$, as 
TABLE 1: Empirical values of $E 0, E s$, and $\beta$ for loess.

\begin{tabular}{|c|c|c|c|c|}
\hline Areas & Liquidity index $I_{L}$ & $E_{0}(\mathrm{MPa})$ & $E_{S}(\mathrm{MPa})$ & $\beta$ \\
\hline \multirow{7}{*}{ Shaanxi Province } & $I_{L}=0.107$ & 31.9 & 2.65 & 12.0 \\
\hline & $I_{L}=0.093$ & 8.7 & 3.53 & 2.5 \\
\hline & $I_{L}<0$ & 2.08 & 5.1 & 0.4 \\
\hline & $I_{L}=0.03$ & 13.97 & 4 & 3.5 \\
\hline & $I_{L}=0.39$ & 74.5 & 3.8 & 19.6 \\
\hline & $I_{L}=0.48$ & 16.7 & 8.43 & 2.0 \\
\hline & $I_{L}=0.23$ & 8.55 & 3.08 & 2.8 \\
\hline \multirow{7}{*}{ Gansu Province } & $I_{L}<0$ & 12.22 & 27.8 & 0.4 \\
\hline & $I_{L}<0$ & 44.9 & 19.3 & 2.3 \\
\hline & $I_{L}=0.56$ & 24 & 3.23 & 7.4 \\
\hline & $I_{L}<0$ & 31.6 & 6 & 5.3 \\
\hline & $I_{L}<0$ & 7.07 & 11 & 0.6 \\
\hline & $I_{L}<0$ & 14.4 & 10.6 & 1.4 \\
\hline & $I_{L}=0.22$ & 21 & 2.21 & 9.5 \\
\hline \multirow{7}{*}{ Qinghai Province } & $I_{L}<0$ & 80.9 & 31.8 & 2.5 \\
\hline & $I_{L}<0$ & 76.2 & 18 & 4.2 \\
\hline & $I_{L}<0$ & 55.5 & 20.4 & 2.7 \\
\hline & $I_{L}<0$ & 67.2 & 37.6 & 1.8 \\
\hline & $I_{L}<0$ & 64.7 & 17.4 & 3.7 \\
\hline & $I_{L}=0.4$ & 31.8 & 8.9 & 3.6 \\
\hline & $I_{L}<0$ & 31.1 & 8.73 & 3.6 \\
\hline
\end{tabular}

TABLE 2: The relationship between $\beta$ and $e$.

\begin{tabular}{lccccccccccc}
\hline Items & \multicolumn{10}{c}{ Void ratio $e$} \\
& $0.41 \sim 0.50$ & $0.51 \sim 0.60$ & $0.61 \sim 0.70$ & $0.71 \sim 0.80$ & $0.81 \sim 0.90$ & $0.91 \sim 1.00$ & $1.01 \sim 1.10$ & $1.11 \sim 1.20$ & $1.21 \sim 1.30$ & $1.31 \sim 1.40$ & $1.41 \sim 1.50$ \\
\hline Clay $(\beta)$ & 4.2 & 4.2 & 3.7 & 3.0 & 2.2 & - & - & - & - & - & - \\
Silty clay $(\beta)$ & 5.0 & 4.8 & 4.5 & 3.9 & 3.2 & 2.6 & 2.1 & - & - & - & - \\
Silt $(\beta)$ & - & - & 6.0 & 6.0 & 5.8 & 5.4 & 4.8 & 4.1 & 3.4 & 2.7 & 2.0 \\
\hline
\end{tabular}

well as $\beta$ in different areas of China, as shown in Table 1. Additionally, the empirical value of $\beta$ with variable $e$ based on a large amount of computational analysis is given by the China Architectural Design and Research Institute [23] as listed in Table 2.

2.3.3. Determination Approaches of Deformation Modulus $E_{0}$. (1) Plate Load Test. According to the plate load test, the following formula can be given as [24]

$$
E_{0}=\frac{\xi\left(1-v^{2}\right) p_{1} B}{S_{1}}
$$

where $\xi$ refers to the shape factor of the load plate, which can be 0.88 for a square plate and 0.79 for a circular plate; $B$ denotes the side length or diameter of the load plate; $S_{1}$ represents the settlement at the proportional limit $p_{1}$ according to the $p$-S curve. If the straight section of the $p-S$ curve is not significant, then make $S_{1}=0.02 B$ for clay and $S_{1}=(0.01 \sim 0.015) B$ for sandy soil.

(2) Pressuremeter Test. According to the pressuremeter test, the following formula can be given:

$$
E_{0}=\frac{M\left(1-v^{2}\right) p_{1} a^{2}}{S_{1}},
$$

where $p_{1}$ refers to the proportional limit of the straight section of the test curve and $S_{1}$ denotes the stable value of the reduced water level in the buret at $p_{1} ; a$ and $M$ are the radius of the borehole and the lateral pressure coefficient, respectively; and $M=2930 \mathrm{~m}^{-1}$ for Quaternary clay.

(3) Empirical Approaches Based on $\beta$. If the plate load test and pressuremeter test cannot be carried out, the value of $E_{s}$ can be measured by an indoor laboratory test. Afterward, $E_{0}$ can be calculated by referring to the empirical values of $\beta$ summarized in Section 2.3.2.

2.4. Determination of Deformation Modulus $E_{O S}$ of Loess upon Wetting. The deformation modulus $E_{0 S}$ of loess upon wetting can be measured directly by a field load test if it is possible. According to the practical statistical analysis based on numerous load tests [25], the curves of compressive modulus $E_{S}$ and deformation modulus $E_{0 S}$ versus water content $\omega$ for loess with the void ratio of $e=1.0$ under a ranged pressure from 50 to $150 \mathrm{kPa}$ can be illustrated in Figure 1. 


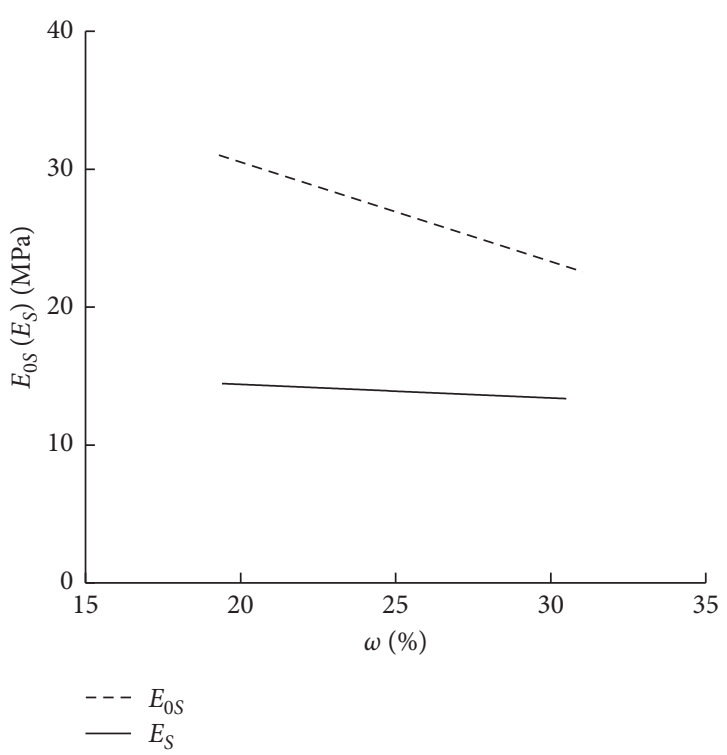

Figure 1: Curves of $E_{0}\left(E_{s}\right)$ versus $\omega(e=1.0)$.

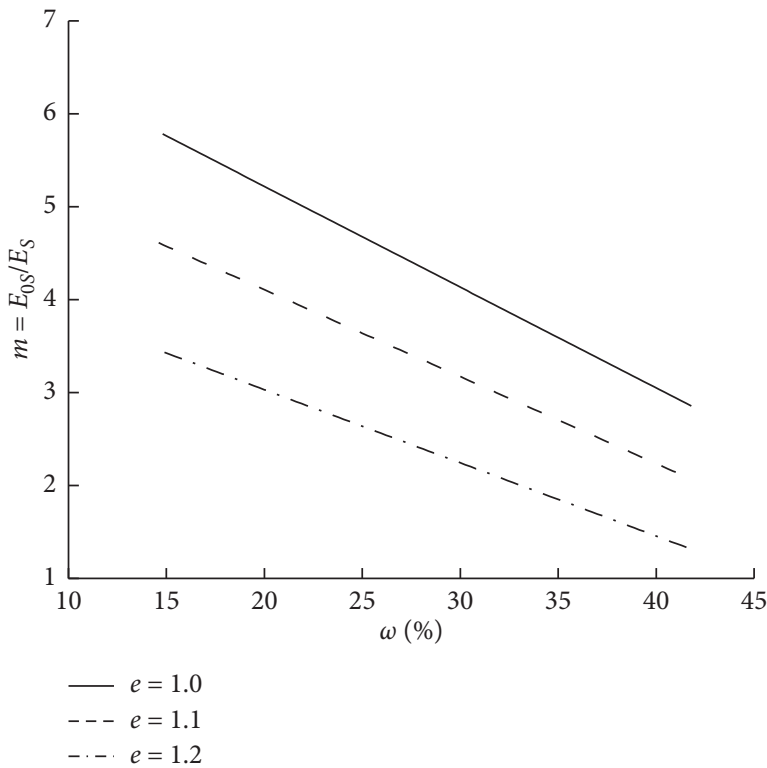

FIgURE 2: The relationship between $m$ and $\omega$ under different $e$.

As shown in Figure 1, the deformation modulus $E_{0 S}$ is constantly larger than the compressive modulus $E_{S}$ and the difference between $E_{0 S}$ and $E_{S}$ decreases as the water content $\omega$ increases. The relationship between the ratio of $E_{0 S}$ to $E_{S}$, which is labeled as $m$, and water content $\omega$ under different void ratios is shown in Figure 2.

It can be seen from Figure 2 that a majority of the deformation modulus $E_{0 S}$ are more significant than the compressive modulus $E_{S}$. The value of $m$ varies in the following range: $e=1.0, m=1.98 \sim 3.83$, with a mean of 2.90 ; $e=1.1, \quad m=1.20 \sim 3.86$, with a mean of $2.03 ; \quad e=1.2$, $m=0.61 \sim 4.39$, with a mean of 2.50 . According to the statistic data [25], the following relationship between $m$ and $e$ for loess can be established as

$$
m \cdot e=2.718,
$$

Based on a large number of test results [26], the relationship between the compressibility $a$ and the water content $\omega$ for loess can be concluded as $\lg a=0.0814 w-3.580$, $e=0.5 \sim 0.7 ; \quad \lg a=0.1039 w-3.975, \quad e=0.7 \sim 0.9$; $\lg a=0.0935 w-3.252, \quad e=0.9 \sim 1.1 ; \quad \lg a=0.0950 w-2.856$, $e=1.1 \sim 1.3$. At this point, the compressibility of loess upon wetting can be estimated accordingly. Then the compressive modulus $E_{s}$ can be calculated by equation (11), and the deformation modulus $E_{0 s}$ of loess upon wetting can be attained through conversion based on the empirical ratio $m$ recommended in equation (16) as

$$
E_{0 s}=m E_{s}=\frac{2.718\left(1+e_{0}\right)}{a e} .
$$

In addition, Jiao [27] proposed a new parameter (chord modulus $E_{c}$ ) to calculate the nonlinear deformation of foundation according to the incremental method for solving the nonlinear problem. Jiao [27] suggested that the chord modulus $E_{c}$ is closely related to the physical indices of soil based on numerous data concerning the relationships of the chord modulus with void ratio and water content of ordinary loess obtained through load tests. The parameter $E_{c}$ is obtained by utilizing the principle that the deformation is piecewise calculated and then superposed to obtain the total deformation based on the deformation curve:

$$
E_{c}=\left(1-v^{2}\right) \frac{\Delta P_{i} \cdot F}{\Delta S_{i} \cdot d},
$$

where $\Delta P_{i}$ refers to the increment in the last section of the additional stress point $P_{i}$ in a $P-S$ curve, which can be $25 \mathrm{kPa}$ in general; $\Delta S_{i}$ represents the incremental settlement corresponding to $\Delta P_{i} ; F$ and $d$ denote the converted area and diameter of the load plate, respectively.

With the increment of water content, the chord modulus reduces, and the specific values can be found in Jiao's literature [27]. It has been proven effective in multiple practical engineering by using chord modulus to calculate the deformation of loess upon wetting. Therefore, it is feasible to obtain $E_{s 0}$ based on the chord modulus when there is no testing data.

\section{Comparison of Modulus Reduction Method and Force-Water Equivalent Method}

In order to further investigate the applicability of the modulus reduction method, a simple calculation model is established based on FLAC3D, as shown in Figure 3. The numerical model has a full mesh of $20 \times 20 \times 10$, of which the central part is the loess unit being subjected to collapse, and the rest of the mesh represents noncollapsible loess units. The mechanical behavior of the soil obeys the rule of the Mohr-Coulomb model.

Concerning the modulus reduction method, the deformation of soil is triggered by additional stress generated by increased bulk density, which belongs to body force, distributed in the whole body of the deformed soil (soil with 


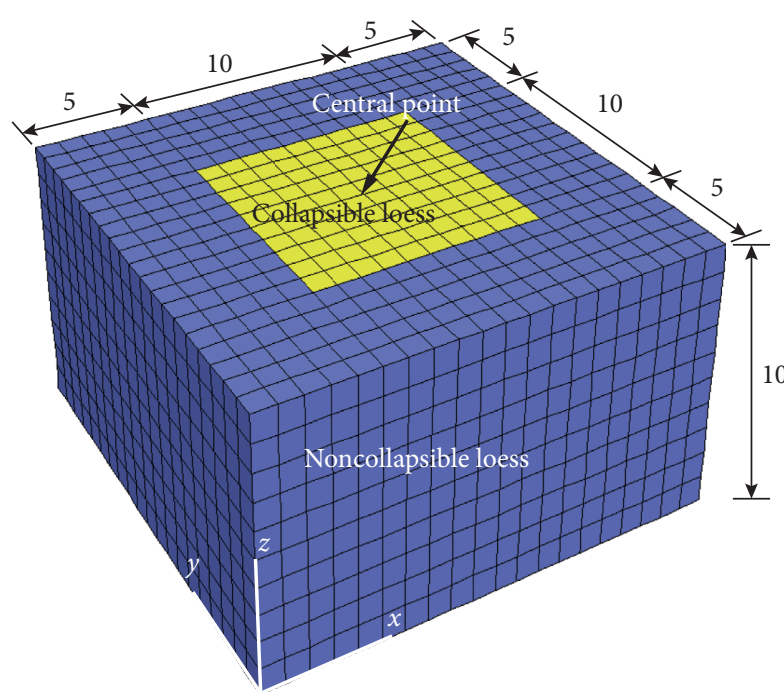

Figure 3: Mesh layout of the calculation model (unit: m).

reduced modulus). In the modulus reduction method, the deformation occurs with no dependence on any external force but the changing parameters of the soil. In the forcewater equivalent method, the uniform load applied on the soil triggers the deformation of soil while the soil parameters remain unchanged. The principle of the force-water equivalent method is to apply pressure on the surface of the soil layer to simulate the collapsible deformation of loess upon wetting. Therefore, the uniform pressure applied on the surface of the soil, as illustrated in Figure 4(b), is not caused by the superstructure. The application of uniform pressure is equivalent to the effect of water on loess to some extent to force the occurrence of displacement, which can be used to analyze the equivalent amount of collapsible deformation $[4,5]$. The schematic diagram of the two methods is illustrated in Figure 4, and the input calculation parameters are displayed in Table 3. To facilitate the comparison, the maximum calculated displacements on the surface of the soil, that is, the displacement of the central point, based on the two methods, are approximately the same. In other words, the value of the pressure applied to the model in Figure 4(b) can be backcalculated by trial simulations based on the maximum displacement of the model in Figure 4(b), which should be approximately the same as the maximum displacement of the model in Figure 4(a).

Figures 5 and 6 show the settlement contours calculated by the modulus reduction method and force-water equivalent method sliced from the middle section, respectively. It can be seen that both the maximum displacements of soil by two methods appear at the middle point on the surface. Meanwhile, the displacement contour derived by the modulus reduction method mainly developed at the depth range of $0 \sim 5 \mathrm{~m}$ (i.e., the range with collapsible loess) and the displacement in the area of noncollapsible loess is minimal. The trend can also be observed in the result of the force-water equivalent method, as illustrated in Figure 7. Nevertheless, the effective contour area obtained by the force-water equivalent method is significantly larger than that derived by the modulus reduction method.
Table 4 displays the $z$-directional displacements of soil layers at different depths calculated by the two methods. The maximum deformation appears in the soil layers at the depth range of $4 \sim 5 \mathrm{~m}$ (i.e., bottom soil layers of collapsible loess) obtained from the modulus reduction method. By contrast, the maximum deformation appears at the upper soil layers of collapsible loess based on the force-water equivalent method. The reason is that the distribution of additional stress in the soil is different along the direction of depth under the effects of body force and surface uniform load. To be specific, the additional stress induced by increased bulk density gradually increases along the direction of depth while that caused by surface uniform load declines along the direction of the depth.

It can be seen from Table 4 that the deformation of collapsible loess layers is $14.0 \mathrm{~mm}$ by using the modulus reduction method, which takes up $93.71 \%$ of the total amount $(14.94 \mathrm{~mm})$, and the deformation of noncollapsible soil layers only accounts for $6.29 \%$. By contrast, the deformation of collapsible loess layers is $10.69 \mathrm{~mm}$ by applying the forcewater equivalent method, which takes up $71.65 \%$ of the total $(14.92 \mathrm{~mm})$ and that of noncollapsible soil layers reaches about $30 \%$ of the total. The results obtained from the forcewater equivalent method do not conform to the conclusion obtained through field tests that no or only insignificant settlement can be observed in the noncollapsible soil layers during the wetting test [11]. In general, the result obtained by the modulus reduction method is more consistent with the collapse mechanism of loess upon wetting compared with that derived by the force-water equivalent method.

\section{Case Study}

4.1. Brief Introduction of the Field Wetting Test. Li et al. [2] have reported a full-scale field wetting test of Pucheng Power Plant, which is located in Weibei loess tableland, Shaanxi Province, China, with vast flat terrain. The elevation of the site above sea level is approximately $495 \mathrm{~m}$. The site soil comprises loess and paleosol, which are interactively distributed layer by layer. The upper part of the soil with a thickness of $6 \mathrm{~m}$ is Malan loess $\left(Q_{3}\right)$, while the lower part exhibits Lishi loess $\left(Q_{1}\right)$ with a total thickness of $60 \mathrm{~m}$. The foundation is composed of loess with considerable thickness, and the layout and characteristics of different layers of foundation soil are shown in Table 5 [2]. According to the survey report, the collapsible loess under overburden pressure at the test site is at grade II based on the accumulative amount of deformation under overburden pressure through laboratory compression test.

The test pit is a cylinder with a diameter of $40 \mathrm{~m}$ and a depth of $1 \mathrm{~m}$, and a $30 \mathrm{~cm}$ thickness of pebble is paved at the bottom. In order to accelerate the saturation of soil in the pit, 140 water-injection holes with a radius of $157 \mathrm{~mm}$ and depth of 32 40 $\mathrm{m}$ are distributed, in which the spacing between the holes is set as $3 \mathrm{~m}$. The influence range of collapse at the horizontal direction is calculated according to the isoline of surface collapse [2]. The moistening boundary extends to the range $45 \sim 50 \mathrm{~m}$ from the edge of the test pit. Moreover, according to the resistivity method for geophysical field 


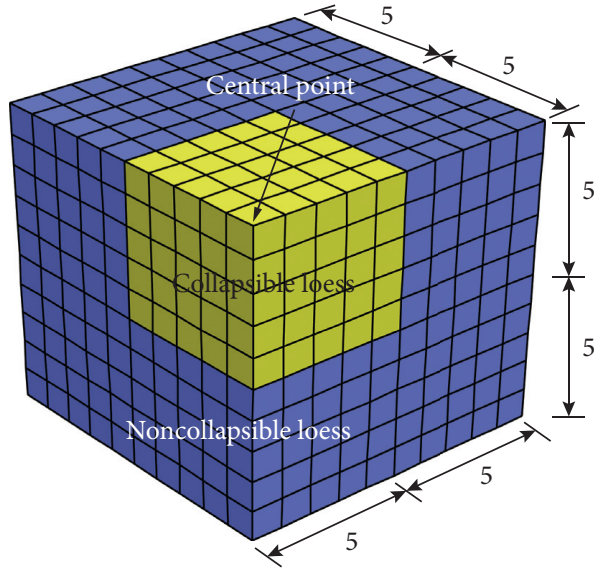

(a)

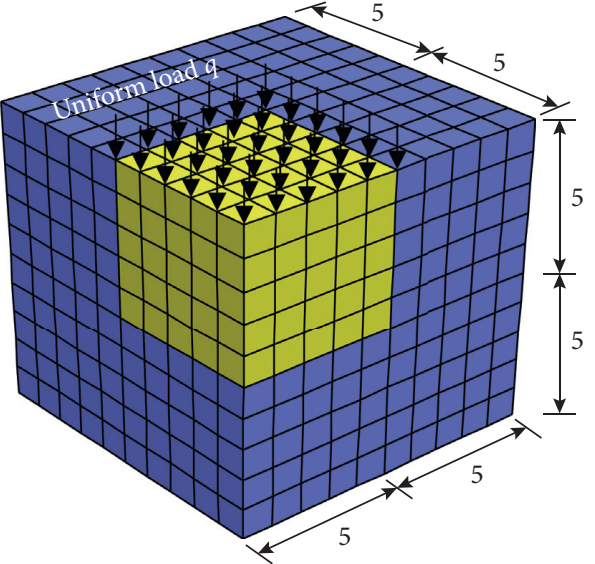

(b)

FIgURE 4: Schematic diagram of two calculation methods (unit: m): (a) modulus reduction method and (b) force-water equivalent method.

TABLE 3: Input parameters comparison.

\begin{tabular}{lccc}
\hline Items & $\begin{array}{c}\text { Original parameters } \\
\text { of loess }\end{array}$ & $\begin{array}{c}\text { Modulus reduction } \\
\text { method }\end{array}$ & $\begin{array}{c}\text { Force-water equivalent } \\
\text { method }\end{array}$ \\
\hline Bulk density in modulus reduced area $\left(\mathrm{kN} / \mathrm{m}^{3}\right)$ & 20 & 22 & 20 \\
Bulk density in other areas $\left(\mathrm{kN} / \mathrm{m}^{3}\right)$ & 20 & 20 & 20 \\
Cohesion $(\mathrm{kPa})$ & 15 & 30 & 15 \\
Internal frictional angle $\left(^{\circ}\right)$ & 30 & 5.14 & 30 \\
Deformation modulus in modulus reduced area $(\mathrm{MPa})$ & 25.7 & 25.7 & 25.7 \\
Deformation modulus in other areas $(\mathrm{MPa})$ & 25.7 & 0.29 & 25.7 \\
Poisson's ratio & 0.29 & - & 0.29 \\
Uniform load applied to the surface of the soil $(\mathrm{kPa})$ & - & & 20 \\
\hline
\end{tabular}
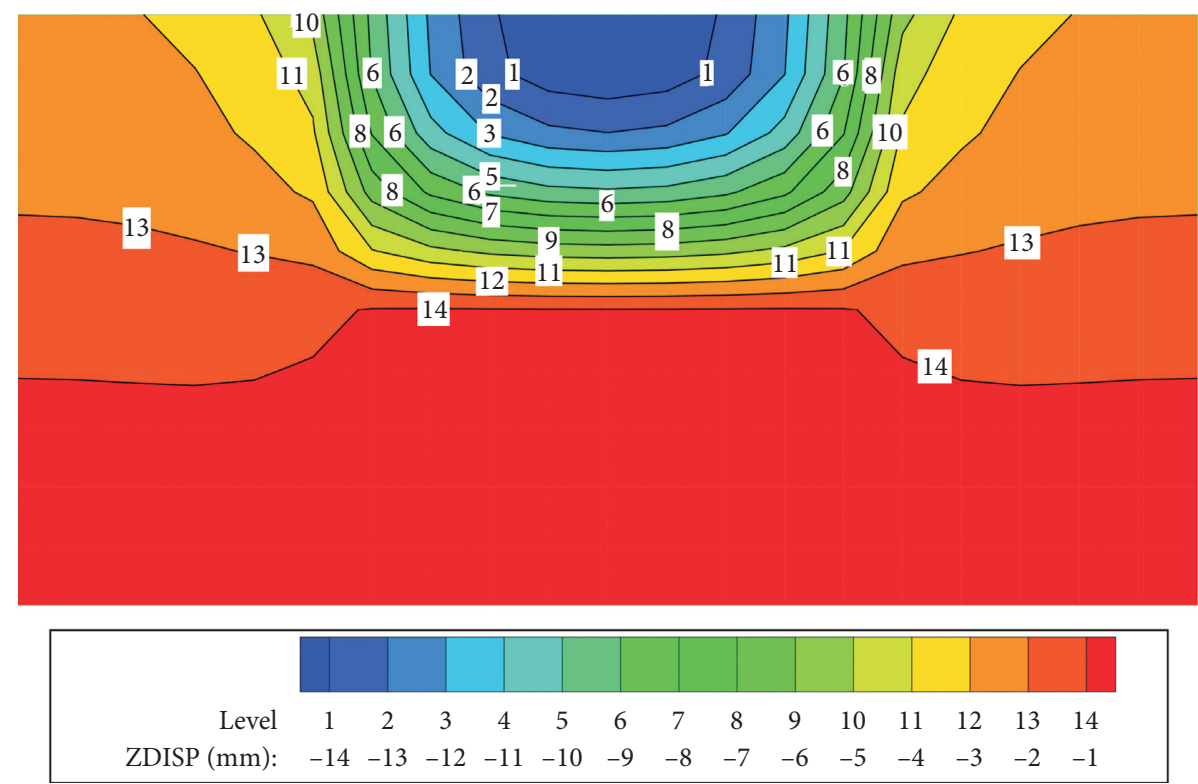

Figure 5: Calculation result of the modulus reduction method. 

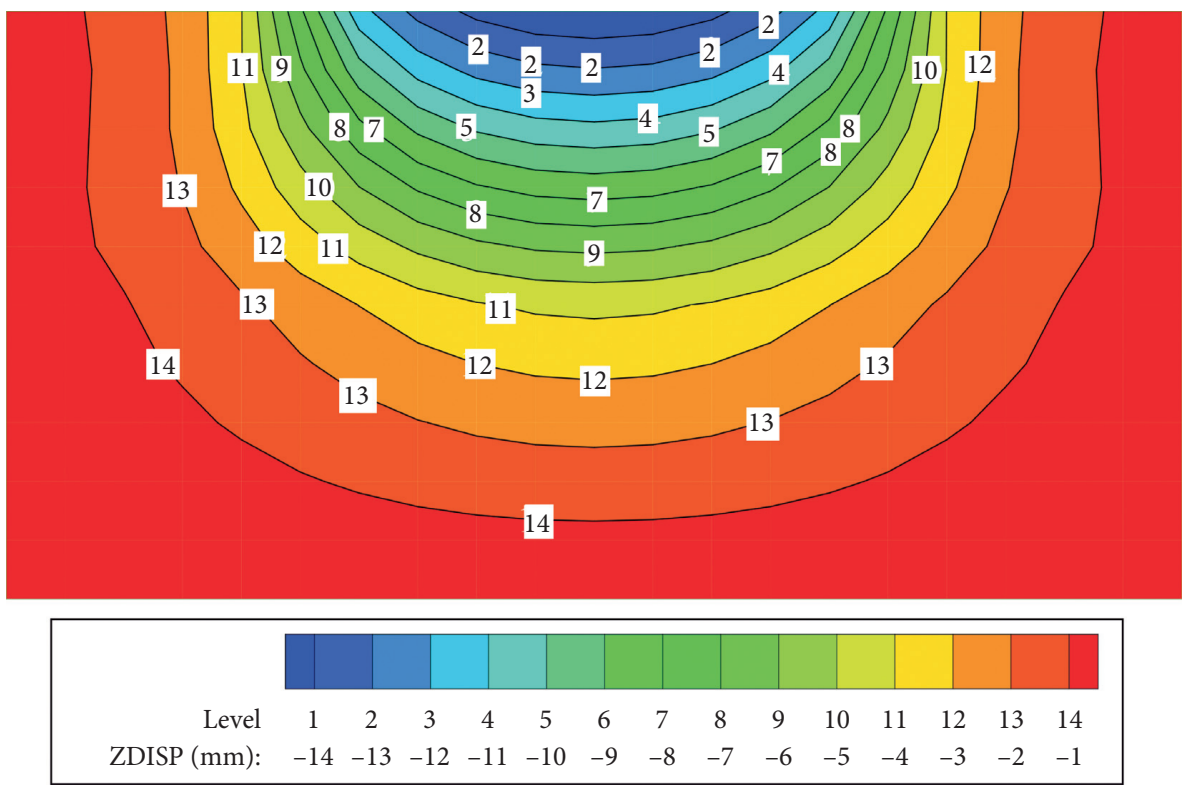

Figure 6: Calculation result of the force-water equivalent method.

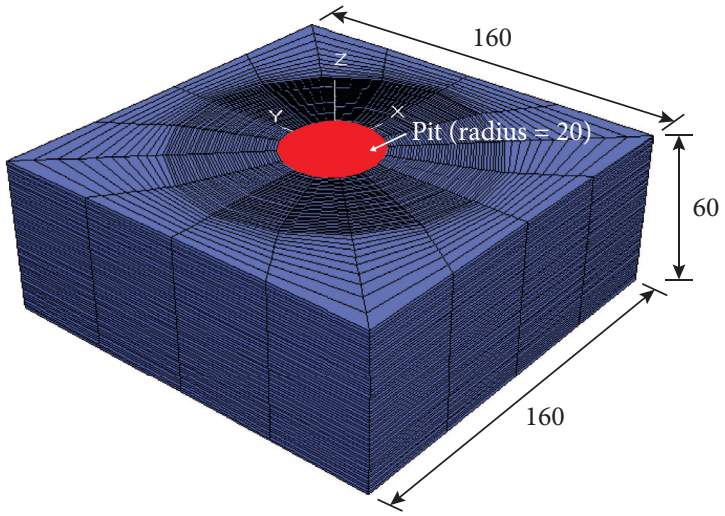

(a)

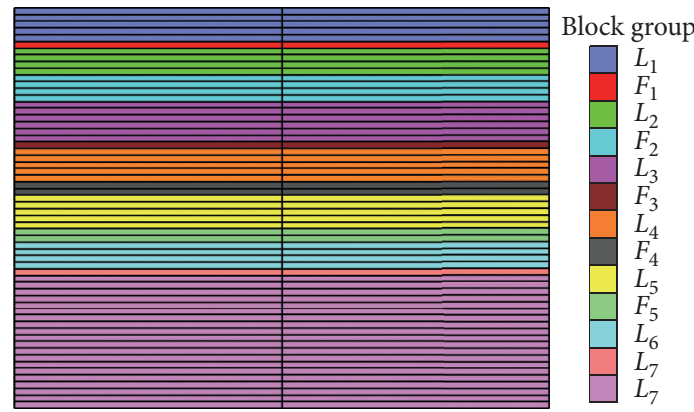

(b)

Figure 7: Numerical model (units: m): (a) grid and mesh and (b) distribution of soil layers.

TABLE 4: Compressive deformation of soil layers at different depths (unit: $\mathrm{mm}$ ).

\begin{tabular}{|c|c|c|c|c|c|c|c|c|c|c|c|c|}
\hline \multirow[t]{2}{*}{ Items } & \multicolumn{10}{|c|}{$\begin{array}{l}\text { Depth range of } \\
\text { soil layers }(\mathrm{m})\end{array}$} & \multirow{2}{*}{$\begin{array}{c}\text { Deformation of collapsible } \\
\text { loess layers }\end{array}$} & \multirow{2}{*}{$\begin{array}{c}\text { Total } \\
\text { deformatior }\end{array}$} \\
\hline & $0 \sim 1$ & $1 \sim 2$ & $2 \sim 3$ & $3 \sim 4$ & $4 \sim 5$ & $5 \sim 6$ & $6 \sim 7$ & $7 \sim 8$ & $8 \sim 9$ & $9 \sim 10$ & & \\
\hline Modulus reduction method & 0.20 & 1.75 & 3.14 & 4.3 & 4.61 & 0.22 & 0.21 & 0.18 & 0.17 & 0.16 & 14 & 14.94 \\
\hline Force-water equivalent method & 1.98 & 2.20 & 2.28 & 2.22 & 2.01 & 0.98 & 0.90 & 0.83 & 0.77 & 0.75 & 10.69 & 14.92 \\
\hline
\end{tabular}

prospecting and the test result obtained by electromagnetic induction, the moistening boundary of the test pit being wet is approximately distributed as a circular truncated cone along with the test pit and its vicinity. The influence boundary is about 40 to $50 \mathrm{~m}$ outside the test pit, and the angle of lateral diffusion and permeation of the moistening boundary is about $40^{\circ}$.
4.2. Numerical Modeling Based on Modulus Reduction Method. According to the field test, the test pit has a radius of $20 \mathrm{~m}$. The influence boundary of wetting and collapse extends $40 \mathrm{~m}$ outwards the test pit and is $20 \mathrm{~m}$ from the calculation boundary. At the vertical direction upwards, the thickness of collapsible soil layers is $40 \mathrm{~m}$, while that of noncollapsible soil layers takes $20 \mathrm{~m}$ along the vertical direction downwards. On 
TABLE 5: Layout of soil layers.

\begin{tabular}{|c|c|c|c|c|c|}
\hline $\begin{array}{l}\text { Stratigraphic } \\
\text { chronology }\end{array}$ & Layers & Soil type & $\begin{array}{l}\text { Depth } \\
(\mathrm{m})\end{array}$ & $\begin{array}{c}\text { Thickness } \\
(\mathrm{m})\end{array}$ & Description \\
\hline \multirow[b]{2}{*}{$Q_{3}$} & $L_{1}$ & Loess & 5.2 & 5.2 & $\begin{array}{l}\text { The slightly wet brown-yellow loess is hard and plastic and shows uniform } \\
\text { quality, developed pores, and visible wormholes and snail shells }\end{array}$ \\
\hline & $F_{1}$ & Paleosoil & 6.4 & 1.2 & $\begin{array}{c}\text { The slightly wet bronzing hard paleosoil is hard and plastic and shown as } \\
\text { fragments. The soil is loosened and contains medium-developed pores } \\
\text { and plenty of calcareous concretions }\end{array}$ \\
\hline \multirow{10}{*}{$Q_{2}$} & $L_{2}$ & Loess & 10.4 & 4.0 & $\begin{array}{l}\text { The slightly wet brown-yellow loess is hard and plastic and shows } \\
\text { nonuniform structure, with calcareous concretions, minor snail shells, } \\
\text { and developed pores }\end{array}$ \\
\hline & $F_{2}$ & Paleosoil & 13.8 & 3.4 & $\begin{array}{l}\text { The hard and plastic paleosoil in brown to maroon color (slightly wet to } \\
\text { wet) with nonuniform quality shows few macropores and plenty of } \\
\text { calcareous concretions at the middle and lower parts }\end{array}$ \\
\hline & $L_{3}$ & Loess & 19.9 & 6.1 & $\begin{array}{l}\text { The slightly wet brown-yellow loess with nonuniform structure is hard } \\
\text { and plastic and contains relatively developed pores and a high content of } \\
\text { calcareous concretions at the bottom }\end{array}$ \\
\hline & $F_{3}$ & Paleosoil & 21.4 & 1.5 & $\begin{array}{l}\text { The slightly wetting bronzing hard and plastic paleosoil with uniform soil } \\
\text { quality is dense and shows less developed pores and plenty of calcareous } \\
\text { concretions at the lower part }\end{array}$ \\
\hline & $L_{4}$ & Loess & 26.5 & 5.1 & $\begin{array}{l}\text { The slightly wet pale yellow loess is hard and plastic and exhibits uniform } \\
\text { quality and medium-developed pores }\end{array}$ \\
\hline & $F_{4}$ & Paleosoil & 27.4 & 0.9 & $\begin{array}{l}\text { The slightly wet bronzing hard and plastic paleosoil with uniform quality } \\
\text { contains less developed macropores and few calcareous concretions at the } \\
\text { lower part }\end{array}$ \\
\hline & $L_{5}$ & Loess & 33.3 & 5.9 & $\begin{array}{l}\text { The slightly wet tawny loess which has uniform quality and is dense is } \\
\text { hard and plastic and hardly shows macropores, with calcareous } \\
\text { concretions in local zone }\end{array}$ \\
\hline & $F_{5}$ & Paleosoil & 35.2 & 1.9 & $\begin{array}{l}\text { The slightly wet maroon paleosoil with nonuniform quality is hard and } \\
\text { plastic and exhibits fragment structure, nondeveloped macropores, and } \\
\text { many calcareous concretions }\end{array}$ \\
\hline & $L_{6}$ & Loess & 39.0 & 3.8 & $\begin{array}{c}\text { The slightly wet isabellinus loess is hard, plastic, and dense and shows } \\
\text { uniform quality and nondeveloped pores }\end{array}$ \\
\hline & $L_{7}$ & Loess & $>41.0$ & $>2.0$ & $\begin{array}{l}\text { The slightly wet bronzing loess (hard and plastic to hard) presents } \\
\text { uniform quality and is dense. It contains minor calcareous concretions }\end{array}$ \\
\hline
\end{tabular}

TABLE 6: The calculation parameters of various soil layers.

\begin{tabular}{|c|c|c|c|c|c|c|c|c|c|}
\hline Layers & $\begin{array}{l}\text { Depth } \\
\text { (m) }\end{array}$ & $\begin{array}{l}\text { Thickness } \\
\text { (m) }\end{array}$ & $\begin{array}{l}\text { Cohesion } \\
(\mathrm{kPa})\end{array}$ & $\begin{array}{c}\text { Internal } \\
\text { frictional } \\
\text { angle }\left(^{\circ}\right) \\
\end{array}$ & $\begin{array}{c}\text { Natural bulk } \\
\text { density }(\mathrm{kN} / \\
\left.\mathrm{m}^{3}\right)\end{array}$ & $\begin{array}{c}\text { Saturated bulk } \\
\text { density }(\mathrm{kN} / \\
\left.\mathrm{m}^{3}\right)\end{array}$ & $\begin{array}{c}\text { Compressive } \\
\text { modulus (MPa) }\end{array}$ & $\begin{array}{c}\text { Deformation } \\
\text { modulus (MPa) }\end{array}$ & $\begin{array}{l}\text { Poisson's } \\
\text { ratio }\end{array}$ \\
\hline$L_{1}$ & 5 & 5 & 15 & 24 & 14.3 & 17.2 & 3 & 6 & 0.37 \\
\hline$F_{1}$ & 6 & 1 & 40 & 25 & 17.5 & 19.0 & 20 & 30 & 0.37 \\
\hline$L_{2}$ & 10 & 4 & 40 & 18 & 17.0 & 18.7 & 25 & 38 & 0.41 \\
\hline$F_{2}$ & 14 & 4 & 50 & 24 & 17.6 & 19.0 & 20 & 30 & 0.37 \\
\hline$L_{3}$ & 20 & 6 & 40 & 25 & 16.5 & 18.5 & 10 & 15 & 0.37 \\
\hline$F_{3}$ & 21 & 1 & 70 & 25 & 17.5 & 19.0 & 25 & 38 & 0.37 \\
\hline$L_{4}$ & 26 & 5 & 40 & 20 & 16.8 & 19.0 & 12 & 18 & 0.40 \\
\hline$F_{4}$ & 28 & 2 & 70 & 25 & 18.0 & 18.3 & 20 & 30 & 0.37 \\
\hline$L_{5}$ & 33 & 5 & 50 & 25 & 17.2 & 19.3 & 15 & 27 & 0.37 \\
\hline$F_{5}$ & 35 & 2 & 75 & 24 & 18.5 & 18.8 & 45 & 54 & 0.37 \\
\hline$L_{6}$ & 39 & 4 & 50 & 30 & 18.5 & 19.5 & 40 & 48 & 0.33 \\
\hline$L_{7}$ & 40 & 1 & 80 & 30 & 19.0 & 19.5 & 80 & 80 & 0.33 \\
\hline$L_{7}$ & 60 & 20 & 80 & 30 & 19.0 & 19.5 & 80 & 80 & 0.33 \\
\hline
\end{tabular}

this basis, a calculation model with its dimension of $160 \mathrm{~m} \times 160 \mathrm{~m} \times 60 \mathrm{~m}$ (length $\times$ width $\times$ height $)$ is established, totally containing 67,200 zones and 68,381 grid points, as shown in Figure 7(a). The test pit and the external influence zone of immersion and collapse outside the test pit are distributed as a circle, as shown in Figure 7(a). In the calculation model, the soil is partitioned into 13 layers from top to bottom; as shown in Figure 7(b), the physical and mechanical parameters of various soil layers are displayed in Table 6. 
TABLE 7: Reduction of deformation modulus (unit: MPa).

\begin{tabular}{lcccccccccccc}
\hline Layers & $L_{1}$ & $F_{1}$ & $L_{2}$ & $F_{2}$ & $L_{3}$ & $F_{3}$ & $L_{4}$ & $F_{4}$ & $L_{5}$ & $F_{5}$ & $L_{6}$ & $L_{7}$ \\
\hline$E_{0}$ & 6 & 30 & 38 & 30 & 15 & 38 & 18 & 30 & 27 & 54 & 48 & 80 \\
$\zeta$ & 1.00 & 0.40 & 0.26 & 0.44 & 0.59 & 0.42 & 0.57 & 0.69 & 1.00 & 0.71 & 0.92 & 0.83 \\
$E_{0 s}$ & 6 & 12 & 10 & 13.3 & 8.9 & 15.8 & 10.2 & 20.6 & 27 & 38.5 & 44 & 66.7 \\
\hline
\end{tabular}
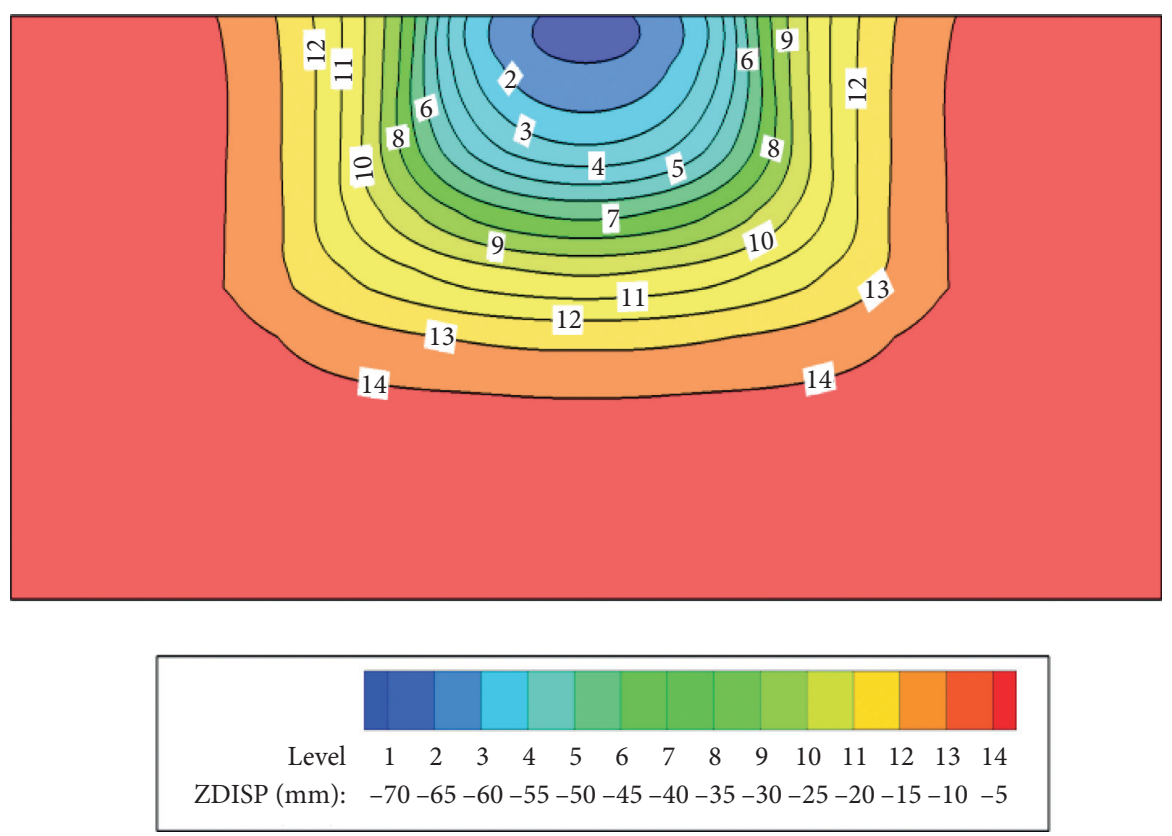

Figure 8: Contour of $z$-directional (vertical) displacement at the section of $y=0$.

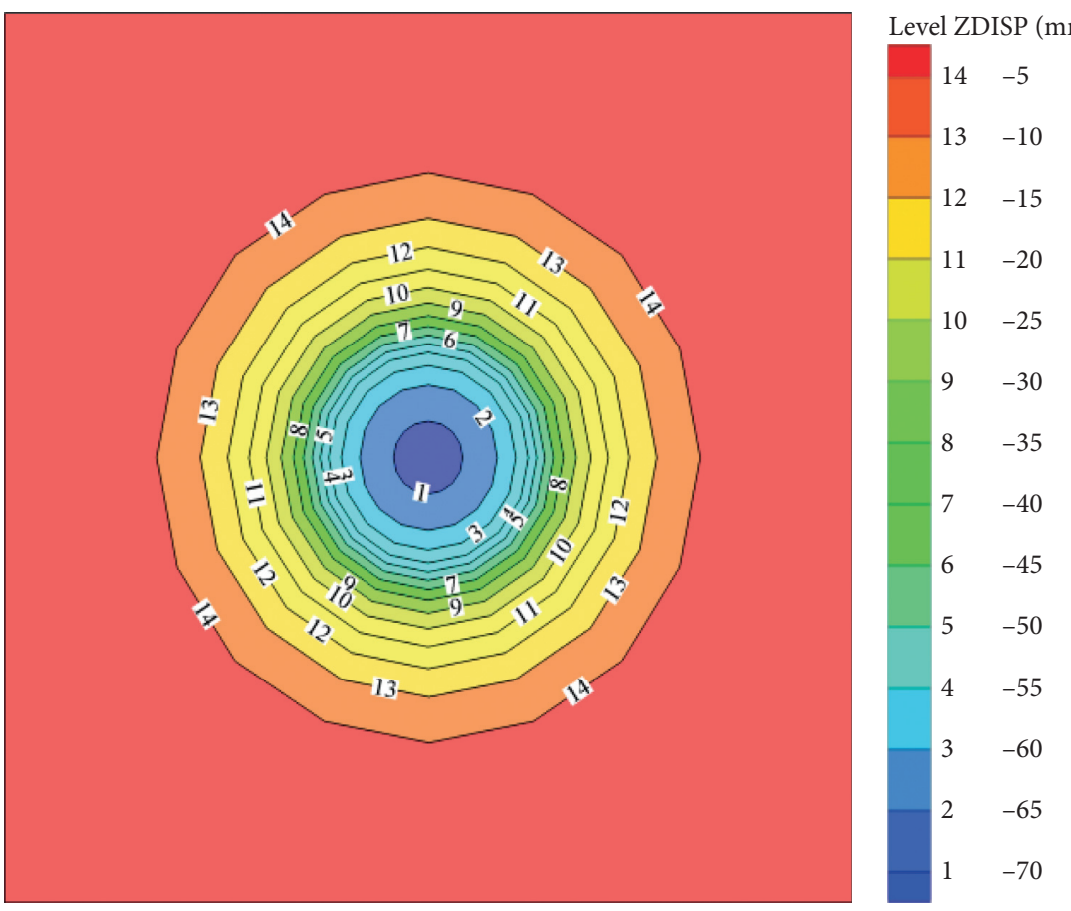

Figure 9: Contour of $z$-directional (vertical) displacement (top view). 
In the investigations of literature [28], the water contents of soil in the vicinity of the multiple test pits of loess upon wetting at different depths were measured, and the result showed that the influence range of immersion generally extended from the edge of test pits to the periphery at the angle of $40^{\circ} \sim 50^{\circ}$. In the test concerning loess collapse in Pucheng Power Plant, the angle of lateral diffusion and permeation of moistening boundary was about $40^{\circ}$, which conformed to the range of diffusion angle obtained in the literature [29]. For the convenience of modeling, the diffusion angle is set as $45^{\circ}$ in the calculation model. The reduction of deformation modulus is based on the description in Section 2.4, and the relevant results can be found in Table 7.

After establishing the numerical model, the material parameters in Table 6 are assigned to the soil blocks. After setting the gravitational acceleration and boundary, the stress field of the model under the effect of overburden pressure is first calculated. Subsequently, the displacement is reset to increase bulk density and reduce the modulus of collapsible loess. The calculated displacement of soil is the deformation after rebalancing.

4.3. Analysis of the Calculation Results. Figures 8 and 9 show the $z$-directional (vertical) displacements obtained through numerical simulation. On the surface, the center of the test pits exhibits the largest amount of deformation during the collapse, and the influence range of wetting gradually extends from the edge of the test pits to periphery, appearing like a circle. The vertical deformation of the surface (settlement) during collapse also gradually decreases from the test pits to the periphery, as shown in Figure 9. In the vertical direction, the area with the largest deformation can be found on the surface of the central pit. Along the direction of depth downwards, the $z$-directional displacement of soil gradually decreases and approaches zero at the boundary between the collapsible and noncollapsible loess. In other words, the collapse of soil only appeared in collapsible loess layers.

Figure 10 shows the displacement vector of soil in the area influenced by wetting around the test pits at the section of $y=0$. In the test pits and the area below (i.e., area I, as illustrated in Figure 10), the soil moves downwards along the vertical direction. Extending outwards from the edge of the test pits, the soil in area II near the surface does not directly undergo collapse. However, the soil in area II is subjected to displacement downwards inclined to the direction of area I under the pull-down effect due to the collapse of soil in area I and the collapsing effect in area III. Moreover, the soil upon wetting in the middle and lower parts of area III undergoes not only downward displacement but also certain lateral displacement. The trend becomes increasingly significant while extending horizontally outwards from the edge of the test pits. These disciplines reflected by the numerical results are highly consistent with the measured results by Liu [25] and Meng [24].

Figure 11 displays the vertical displacements at the central point of the test pits and the points below the central

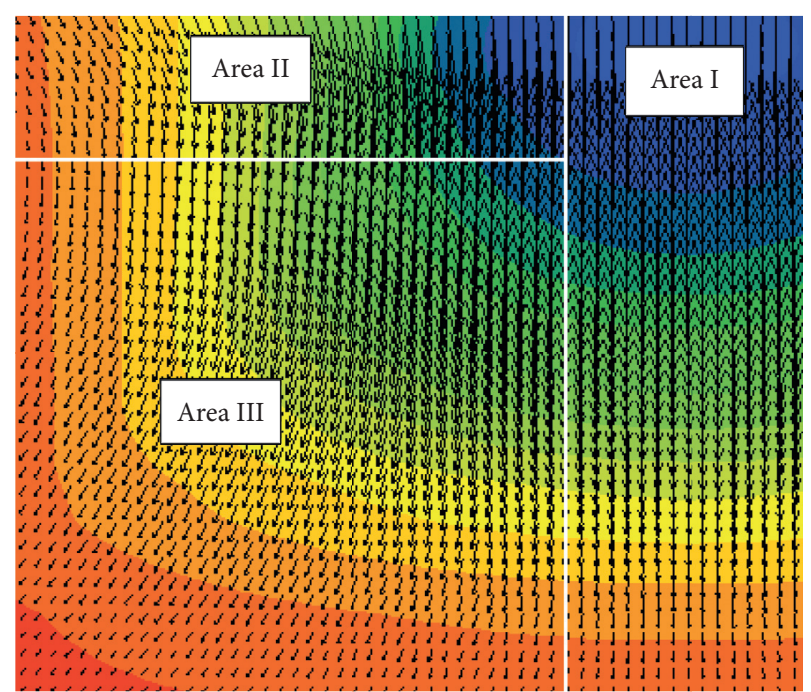

FIgURE 10: The $z$-directional displacement vector at the section of $y=0$.

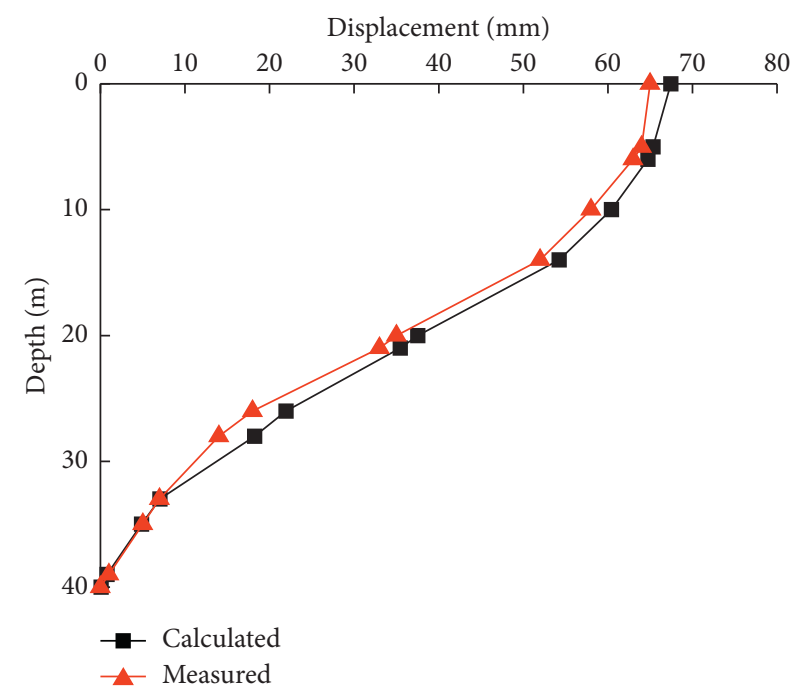

Figure 11: Comparison of the vertical layered displacements at and below the central point.

point at which the dividing point of collapsible soil layers locates. It can be clearly seen from Figure 11 that the result obtained by using the modulus reduction method agrees excellently well with the measured result.

\section{Conclusions}

From the perspective of mechanism and deformation characteristics of collapsible loess, a simplified method named modulus reduction method, which is based on the principle of strength reduction, is proposed in this paper to estimate the collapsible behavior of loess. The modulus reduction method simulates the loess collapse under overburden pressure by reducing the deformation modulus and increasing the bulk density.

Subsequently, the feasibility of the modulus reduction method is first compared with the force-water equivalent 
method, which is commonly used in the NSF analysis of piles, based on the same numerical model. The results derived from the modulus reduction method are found to be more consistent with the mechanism of collapsible loess.

At last, a published case history concerning the field test of loess upon wetting is used to validate the calculation results of modulus reduction. The result obtained through numerical simulation shows that the collapse of soil only appears in collapsible loess layers, and the center of the test pits shows the most significant amount of deformation during the collapse. The influence range of wetting extends as a circle from the edge of the test pits to the periphery, and the amount of deformation during collapse gradually declines. The deformation characteristics of collapsible soil layers obtained based on numerical simulation are consistent with the result of the field test.

In the case of providing reasonable and accurate calculation parameters, the modulus reduction method can quantitatively analyze the deformation behaviors of collapsible loess under overburden pressure. Moreover, the method can also accurately calculate the total deformation of collapsible loess under overburden pressure and deformation of various soil layers. The modulus reduction method favorably solves the numerical simulation on the collapse of loess. It can provide a favorable basis for conducting the numerical simulation, especially for the analysis of NSF, on various deep foundations such as pile foundation in collapsible loess.

\section{Data Availability}

The authors confirm that the data supporting the findings of this study are available within the article.

\section{Conflicts of Interest}

The authors declare that they have no conflicts of interest.

\section{Acknowledgments}

This research was supported by the China Scholarship Council and the Sichuan Science and Technology Program (no. 2019YJ0323) as well as the National Nature Science Foundation of China (no. 42007247).

\section{References}

[1] Xi'an Metallurgy and Architecture College, "Test study on self-weight collapsible loess of Weibei Zhangqiao," Journal of Xi'an Metallurgy and Architecture College, vol. 2, no. 2, pp. 50-76, 1976.

[2] D. Li, Y. He, and G. Sui, "Study and test on immersion of Q2 loess in large area," Chinese Journal of Geotechnical Engineering, vol. 15, no. 2, pp. 1-11, 1993.

[3] S.-J. Feng, F.-L. Du, Z.-M. Shi, W.-H. Shui, and K. Tan, "Field study on the reinforcement of collapsible loess using dynamic compaction," Engineering Geology, vol. 185, pp. 105-115, 2015.

[4] Z. Wang, Y. Xie, J. Qiu, Y. Zhang, and H. Fan, "Field experiment on soaking characteristics of collapsible loess,"
Advances in Materials Science and Engineering, vol. 2017, Article ID 6213871, 17 pages, 2017.

[5] Y. Zhang, Z. Hu, H. Chen, and T. Xue, "Experimental investigation of the behavior of collapsible loess treated with the acid-addition pre-soaking method," KSCE Journal of Civil Engineering, vol. 22, no. 11, pp. 4373-4384, 2018.

[6] Y. K. Chow, J. T. Chin, and S. L. Lee, "Negative skin friction on pile groups," International Journal for Numerical and Analytical Methods in Geomechanics, vol. 14, no. 2, pp. 75-91, 1990.

[7] B. Indraratna, A. S. Balasubramaniam, P. Phamvan, and Y. K. Wong, "Development of negative skin friction on driven piles in soft Bangkok clay," Canadian Geotechnical Journal, vol. 29, no. 3, pp. 393-404, 1992.

[8] C. J. Lee, M. D. Bolton, and A. Al-Tabbaa, "Numerical modelling of group effects on the distribution of dragloads in pile foundations," Géotechnique, vol. 52, no. 5, pp. 325-335, 2002.

[9] E. M. Comodromos and S. V. Bareka, "Evaluation of negative skin friction effects in pile foundations using $3 \mathrm{D}$ nonlinear analysis," Computers and Geotechnics, vol. 32, no. 3, pp. 210-221, 2005.

[10] J. Liu, H. Gao, and H. Liu, "Finite element analyses of negative skin friction on a single pile," Acta Geotechnica, vol. 7, no. 3, pp. 239-252, 2012.

[11] J. Li, Y. Xie, and Z. Feng, "Study of the proper pile length in the self-weight collapsible loess," Chinese Journal of Geotechnical Engineering, vol. 24, no. 9, pp. 1629-1634, 2005.

[12] F. Zhou, H. Mi, and Y. Hu, "An constitutive relation for collapsible deformation of loess based on generalized plasticity," Rock and Soil Mechanics, vol. 26, no. 11, pp. 1823-1828, 2005.

[13] A. A. Garakani, S. M. Haeri, C. S. Desai, S. M. Ghafouri, B. Sadollahzadeh, and H. H. Senejani, "Testing and constitutive modeling of lime-stabilized collapsible loess. II: modeling and validations," International Journal of Geomechanics, vol. 19, no. 4, p. 04019007, 2019.

[14] Z. Hu, Z. Shen, and D. Xie, "Constitutive model of structural," Chinese Journal of Rock Mechanics and Engineering, vol. 24, no. 4, pp. 565-569, 2005.

[15] X. Xu, Y. Wang, Z. Yin, and H. Zhang, "Effect of temperature and strain rate on mechanical characteristics and constitutive model of frozen Helin loess," Cold Regions Science and Technology, vol. 136, pp. 44-51, 2017.

[16] J. Li, Study on pile-soil interaction of bridge pile in loess area by test and numerical simulation, Ph.D Thesis, Chang'an University, Xi'an, China, 2006.

[17] A. A. Mustayev and Z. Zhang, Calculation of Ground and Foundation over Collapsible Loess, Water Resources and Electric Power Press, Beijing, China, 1984.

[18] W. Jiao, "Deformation calculation ways and examples of collapsible loess," Building Science Research of Sichuan, vol. 2, no. 4, pp. 16-20, 1984.

[19] J. E. Bowles, Foundation Analysis and Design, McGraw-Hill, New York, NY, USA, 5th edition, 1996.

[20] M. D. Braja, Advanced Soil Mechanics, CRC Press, Boca Raton, FL, USA, 5th edition, 2019.

[21] Itasca Consulting Group Inc, FLAC3D: Fast Lagrangian Analysis of Continua, User's Manual, Minneapolis, MN, USA, 2006.

[22] W. Guan, Engineering Properties of Collapsible Loess, Xi'an Jiaotong University Press, Xi'an, China, 1992. 
[23] China Architectural Design and Research Institute, Calculation of Structures on Elastic Foundation, China Building Industry Press, Beijing, China, 1957.

[24] G. Meng, In-situ Test for Engineering Investigation of Soil and its Engineering Application, Geological Publishing House, Beijing, China, 1998.

[25] Z. Liu, Mechanical and Engineering of Losess, Shaanxi Science and Technology Press, Xi'an, China, 1997.

[26] The Northwest Water Conservancy Science Research Institute, Properties of Northwest Loess, Shaanxi People's Publishing House, Xi'an, China, 1959.

[27] W. Jiao, "New parameters of foundation deformation calculation-principle and application of chord-modulus," Hydrogeology \& Engineering Geology, vol. 1, no. 1, pp. 30-33, 1982.

[28] H. Qian, J. Wang, and Y. Luo, Collapsible Loess Foundation, China Architecture and Building Press, Beijing, China, 1985.

[29] The Foundation Practice Group of Grade 73 Civil and Construction Specialty Construction department, "Test study on foundation of self-weight collapsible loess of coking plant in Shanxi province," Journal of Xi'an Metallurgy and Architecture College, vol. 2, no. 2, pp. 86-118, 1977. 